\title{
FERRAMENTA INTERDISCIPLINAR DE REPRESENTAÇÕES BI E TRIDIMENSIONAIS: THEO VAN DOESBURG E ANDREA PALLADIO
}

Glaucia Augusto Fonseca ${ }^{1}$

\section{Resumo}

Este artigo apresenta um conjunto de idéias sobre como pensar a interdisciplinaridade no curso de Arquitetura e Urbanismo das Faculdades Integradas Bennett. Delineia-se o processo de execução gráfica (bi e tri dimensionais) partindo do conceito da arte do grupo DE STIJL aplicados às obras de Andrea Palladio com a finalidade de apontar como tal processo relaciona-se com as diferentes práticas de interação entre os componentes do currículo. Finalmente, demonstra-se a experiência deste trabalho, buscando-se desta forma, enfatizar os principais objetivos.

Palavras-chave: interdisciplinaridade, Villa Foscari, Palladio, DE STIJL.

\begin{abstract}
This article presents a group of ideas on how to think about how interactive the subjects can be. The process of graphic execution of the Villa Foscari is delineated - work develop by the disciplines of Visual Methodology and Plastic III of the course of Architecture and Urbanism of Faculdades Integradas Bennett. It is shown as such a process link with the different interaction practices among the components of the curriculum. Finally, the experience of this work is demonstrated, being looked for this way, to emphasize the objective principal.
\end{abstract}

Keywords: interactive, Villa Foscari, Andrea Palladio, DE STIJL.

\section{Introdução}

Quando as modernas ciências começaram a se desenvolver, num tempo de mares nunca dantes navegado, conhecer era navegar num oceano de mistérios e riscos. E, para navegar com segurança, seria preciso que cada marujo cuidasse de seu trabalho e buscasse conhecer o máximo sobre ele, sem olhar para o lado. Com o tempo, ficou óbvio que, para vencer travessias mais difíceis, era preciso reconhecer que; na verdade, todos estavam no mesmo barco. O nosso trabalho têm como preceito, a articulação dos mundos físicos e sociais para superar a fragmentação e o distanciamento entre as disciplinas do curso.

E, como o mundo físico e social é um enorme oceano, onde os fenômenos nadam de forma "indisciplinada", é preciso construir essas ferramentas - as competências -, partindo dos conhecimentos específicos e fazendo-os interagir.

Partir dos conhecimentos específicos para entender a relação de sua disciplina com as da mesma área e com todo o currículo. Uma forma de se compreender e aplicar isso é, observar os eixos de competências que estão presentes nas três áreas: representação e comunicação (as linguagens); investigação e compreensão (as ciências); e contextualização sócio-cultural (a sociedade e a cultura).

1 Faculdade de Arquitetura e Urbanismo, Centro Universitário Bennett, Coordenação de Representações Gráficas, UGF / PUC-Rio, Brasil, glaucia@ br.inter.net 


\section{Desenvolvimento do Trabalho}

Como exemplo, escolhemos uma das produções realizada pelos alunos das disciplinas de Metodologia Visual e Plástica III (ambas do $3^{\circ}$ período) do curso de Arquitetura e Urbanismo das Faculdades Bennett.

O trabalho exigiu que cada aluno, das disciplinas acima citadas, propusesse a investigação e pesquisa de uma das inúmeras produções de Andréa Palladio. A opção adotada para exemplificar nosso trabalho, foi a Villa Foscari, obra tratada ao longo do período pela aluna Ana Paula Rocheaud.

Com isso, diferentes domínios de levantamentos foram analisados (pesquisa em fontes bibliográficas, levantamento de plantas, etc) e o conjunto de argumentos construídos pelos alunos, expondo relatórios, debatendo o assunto e confrontando idéias apoiadas nos dados pesquisados a fim enriquecer o repertório dos alunos; evidenciando a multiplicidade de fatores a serem considerados em uma pesquisa.

A aplicabilidade da proposta foi gerar modelos bi e tridimensionais - desenhos com a utilização de diversas técnicas gráficas, elaboração de uma maquete e posteriormente, embasadas nos conceitos do DE STIJL $e$ da escola BAUHAUS, confeccionar um painel.

Sendo assim aplicamos o conceito da arte do grupo DE STIJL $e$ da escola $B A U H A U S$, ao trabalho de Andrea Palladio [1].

Compreender qualquer fenômeno de forma pura e total, é apreender

o que nele há de essencial e imutável.” (EAGLETON, 1982, P.61).

Foi a partir do sofrimento da sociedade européia, produzido pela catástrofe da primeira guerra, que aconteceu uma busca de transformação de valores e, como conseqüência, um grande desenvolvimento das artes e da filosofia. Esses foram anos ricos em movimentos e manifestos, os quais trouxeram importante colaboração para a expressão da modernidade no Ocidente. Foi nesse contexto da Europa que, na Holanda, o grupo De Stijl desenvolvia trabalhos em que enxugava imagens fotográficas e pinturas, reduzindo-as à sua essência, isto é, até se perceber o que nele seria imutável e invariável.

Neste mesmo momento, na Alemanha, os arquitetos da Bauhaus desenvolviam idéias absolutamente análogas ao trabalho racionalista do grupo De Stijl, reduzindo também a forma dos seus objetos de design à sua essência.

O trabalho do movimento holandês De Stjil, principalmente os trabalhos de Theo Van Doesburg e do pintor Piet Mondrian, influenciou todo o campo do design no século XX. O pensamento do De Stijl baseava-se na idéia de que os elementos essenciais dos objetos podem ser mostrados da maneira mais simples possível, com linhas horizontais e verticais e cores primárias - e essenciais - (Neoplasticismo), ou seja, se analisarmos e simplificarmos suficientemente alguma coisa, chegaremos então à sua essência.

Charles Harrison, em Primitivismo, Cubismo e Abstração, diz que "o processo de abstração enfatiza tipicamente aqueles aspectos da pintura que vemos como formais." (HARRISON; FRASCINA; PERRY,1998,P.194). O autor mostra então, um processo de abstração apresentado por Theo Van Doesburg, quando este transforma por etapas um quadro fotográfico de uma vaca numa composição abstrata, intitulada a vaca.

A respeito dessas imagens, dizem ainda os autores de Primitivismo, Cubismo e Abstração [2]:

Dada a sequência das ilustrações de Van Doesburg, podemos realmente participar de uma forma similar de comparação. Se somos informados dos estágios 


\begin{abstract}
intervenientes, podemos com bastante facilidade entender a pintura abstrata como referida à vaca. Isso quer dizer que podemos reconstruir para a pintura um tipo de história causal, que começa, por um lado, com uma vaca real no mundo e, por outro, com um conjunto de intenções por parte do artista.
\end{abstract}

Piet Mondrian procurava o caminho da abstração. Para ele, a pintura abstrata era um passo no sentido da harmonia e do equilíbrio que, acreditava, só poderiam revelar-se descartando-se imagens particulares em favor das universais. $\mathrm{O}$ artista reduziu a sua pintura a uma planimetria de zonas de cor. Os primeiros quadros de Mondrian mostram como ele buscava algo semelhante a Van Doesburg. Segundo Rosemary Lambert, em $A$ arte no século $X X$, Mondrian buscava [3] "aquilo que é constante por trás dos acidentes da aparência". [...] "acreditava que cada coisa particular que vemos, seja uma paisagem, uma árvore ou uma casa, possui uma essência subjacente, e que todas essas essências estão, apesar das aparências, em harmonia. A finalidade do artista é revelar essa estrutura oculta da realidade, essa harmonia universal, em suas pinturas. Seus primeiros quadros mostram-no em busca dessa essência e harmonia".

Rosemary Lambert exemplifica isto muito bem com a série das árvores de Mondrian. Se observarmos as imagens, veremos como o pintor segue em direção à abstração, assim como o quadro A vaca, de Theo Van Doesburg:

$A$ árvore vermelha 1908, é uma pintura expressiva. Ao observá-la, percebemos perfeitamente a árvore e a grama que cresce à sua volta. $A$ árvore cinzenta, 1912, já possui ramos mais retos, passando a ser imagem única naquele espaço. Comenta Rosemary Lambert: "A atividade da árvore é agora vista como parte de uma ação universal, e isso é expresso privando a árvore de seu caráter local, tornando-a, de fato, abstrata".[3]. Em Macieira em flor, 1912, Mondrian busca a harmonia universal. "O tronco e os ramos resumem-se em linhas retas e curvas. Os ramos são o movimento, os espaços entre eles oferecem oposição".[3]

Por sua vez, na Alemanha, a arte da BAUHAUS mostrou forte afinidade com a pintura de Mondrian e com os conceitos básicos do DE STIJL.

Fazendo uma analogia, a arquitetura da $B A U H A U S$ passa a ter maior valor, não pela forma realizada, mas sim pelo esquema gerador desta forma. Era o principio de racionalização do espaço arquitetônico e de qualquer objeto útil à vida do homem, para que se chegasse à essência dos espaços de moradia, de trabalho e do lazer, para o cidadão carente do pós- guerra.

No ensino de arquitetura, sabemos que para se compreender uma determinada obra, é necessário, antes de tudo, entender as intenções do autor, ao gerá-la.

A partir desta idéia da busca da essência da forma, procuramos transferir este processo de abstração para uma obra de Andrea Paladdio, desenvolvendo este trabalho em sala de aula, com a intenção de fazer com que o aluno, ao chegar à essência do seu conteúdo, assimile-a com mais consistência. 


\section{Metodologia e materiais utilizados}

As disciplinas em nossa pesquisa trabalharam concomitantemente. Portanto adotamos uma metodologia de trabalho, que estabelecesse um rígido cronograma a fim de possibilitar aos alunos o pleno desenvolvimento de cada etapa.

Os tópicos desenvolvidos tratavam dos seguintes itens:

Escolha da obra Arquitetônica - definição do tema. Cada aluno pesquisa e escolhe uma obra de Andrea Palladio.

A partir deste momento as observações se dão através de imagens da obra arquitetônica escolhida.Tal como a definição do porque de se trabalhar com este tema, a questão dos objetivos do trabalho, onde e como se pretende alcançar o tema, a abrangência e o cronograma.

1- Pesquisa em fontes bibliográficas

Os dados de nossa informação científica passam por canais informais e formais. Foram adotados três procedimentos: pesquisa documental, pesquisa bibliográfica (apanhado geral sobre os principais trabalhos) e contatos diretos com pesquisadores. As investigações preliminares se deram por estudos exploratórios. Investigando dados históricos, bibliográficos, informações e pesquisas.

2- Levantamento de plantas

Determinação da forma, limites, extensão e localização da obra estudada. Análise de croquis, levantamento das Plantas de Situação, Plantas dos Pavimentos, Planta de Cobertura, Cortes e Vistas.

3- Desenvolvimento dos desenhos e das maquetes

Os grupos de alunos se formam, realizam reuniões e discutem o formato das apresentações, baseando-se nas aulas teóricas de Metodologia Visual e de Plástica III.

4 - Execução de desenhos de observação da maquete segundo os princípios do $D E$ STIJL

5 - Elaboração de um painel seguindo os desenhos de observação dos colegas

\section{Resultados apresentados}

Disciplina de Metodologia Visual e Maquetes

\section{Considerações Finais}

Considera-se que a linha de investigação apresentada neste artigo tem consolidado um referencial metodológico para a atividade docente de elaboração de materiais didáticos para a área gráfica.

Os trabalhos realizados contribuem não só para a área de representação gráfica como também para exercitar a atividade de identificar elementos de saber e processo de constituição dos saberes pode contribuir a estudos aplicados em diferentes áreas do conhecimento.

Destaca-se o interesse em seguir estudando as transformações que sofrem um saber ao transitar por distintos contextos. 


\section{Referências}

[1] EAGLETON, Terry. Teoria da literatura. São Paulo: Martins Fontes, 1982.

[2] HARRISON, Charles; FRASCINA, Francis; PERRY,Gill. Primitivismo, cubismo, abstração : Começo do sec.XX. São Paulo: Cosac \& Naify, 1998.

[4] JAPIASSU, Hilton e MARCONDES, Danilo. Dicionário básico de filosofia. Rio de Janeiro: J. Zahar Editor, 1990.

[3] LAMBERT, Rosemary. A arte do século XX. Universidade de Cambridge, Cambrige,1981. [5] MONDIN, Battista. Introdução à filosofia. São Paulo: Paulinas, 1980.

[6] SILVA, Eloiza Andrade Corrêa da. O Produto Baubau: Seu significado em dois contextos do entreguerras: Alemanha e Estados Unidos. Dissertação de Mestrado. UFF/ IACS.Niterói: 2001. 